DOI: 10.17117/na.2017.01.03.069

Поступила (Received): 23.01.2017

\title{
Жигин В.И.
}

\section{Теоретические основы оценки теплообмена в линии низкого давления системы питания дизелей}

\author{
Zhigin V.I. \\ The theoretical basis for the estimation of heat transfer in low- \\ pressure line of the power supply system of diesel engines
}

Изложены ключевые этапы оценочного расчета теплообмена на участках линии низкого давления системы питания для теоретического исследования изменения теплофизических свойств топлива в зависимости от условий и режимов работы дизеля

Ключевые слова: система питания дизеля, линия низкого давления, теплофизические свойства, теплопередача, теплоотдача, конвекция,

турбулентный, ламинарный

\section{Жигин Владимир Иванович}

Кандидат технических наук, доцент

Рязанское высшее воздушно-десантное командное училище имени генерала армии В.Ф. Маргелова г. Рязань, пл. В.Ф. Маргелова, 1
Set out the key stages of the assessment calculation of heat transfer in areas of low pressure supply system for a theoretical study of changes of the thermophysical properties of fuel depending on conditions and modes of operation of the diesel engine

Key words: power system diesel, low line pressure, thermophysical properties, heat transfer, heat transfer, convection, turbulent, laminar

\section{Zhigin Vladimir Ivanovich}

Candidate of Technical Sciences, Associate Professor Ryazan higher airborne command school named army general V.F. Margelov Ryazan, V.F. Margelov sq., 1

Зависимость теплофизических свойств дизельного топлива от его температуры можно оценить по значению его параметров при данной температуре.

Параметрами, оценивающими теплофизические свойства топлива, являются: плотность дизельного топлива $\rho$ (кг/м3), кинематическая вязкость $v$ (м2/с), удельная теплоемкость С (кДЖ/кг сжимаемость $\alpha,($ м3/Па), температурный коэффициент объемного расширения $\beta,\left(1 /{ }^{\circ} \mathrm{C}\right)$.

Плотность топлива $\rho$ при температуре $\mathrm{t}$ может быть найдена по значению плотности $\rho_{0}$ при нормальных физических условиях $\left(\mathrm{t}_{0}\right)$ из выражения [1]:

$$
\rho=\rho_{o}-10^{4} \times\left(18-13 \times \rho_{o}\right) \times\left(t-t_{o}\right),
$$

Изменение вязкости $v_{\mathrm{t}}$ с изменением температуры может быть найдено по значению вязкости $v_{0}$ при $20^{\circ} \mathrm{C}[1]$ :

$$
v_{t}=v_{o}+\left(1,1 \times v_{o}-0,3\right) \times(1,3-\lg t),
$$

Удельная теплоемкость при постоянном давлении для нефтепродуктов с плотностью $0,73<\rho_{0}<0,96$ может быть вычислена по формуле [1]: 


$$
C_{p 0}=0,403 / \sqrt{\rho_{0}},
$$

Зависимость теплоты парообразования $\mathrm{t}_{\mathrm{sp}}$ от давления, при котором происходит испарение топлива, может быть определена из уравнения [1]:

$$
t_{s p}=t_{s} \times\left[\left(1-\Theta_{\kappa p}\right) /\left(1-\Theta_{s}\right)\right]^{0,4},
$$

Где $\Theta_{\kappa p}=T / T_{\kappa p} u \Theta_{s}=T_{s p} / T_{\kappa p}$ - приведенные температуры.

Изменение коэффициента теплопроводности моторных топлив с повышением температуры с достаточной точностью определяется из выражения, [1]:

$$
\lambda=\lambda_{0} \times(1-\alpha \times t),
$$

где $\lambda_{0}=0,117 / \rho-$ коэффициента теплопроводности при нормальных физических условиях, Вт $/ \mathrm{M} 2 \times К$;

$\alpha=0,0011$ для диапазона температур от $0^{\circ} \mathrm{C}$ до $200^{\circ} \mathrm{C}$.

Уравнение (5) определяет линейный характер зависимости теплопроводности моторных топлив от температуры.

Среднюю величину температурного коэффициента объемного расширения $\beta$ для капельных жидкостей в интервале температур от $t_{\text {ж }}$ до $_{c}$ можно определить из уравнения [2]:

$$
\beta=\left(\rho_{\varkappa}-\rho_{c}\right) /\left[\left(\rho_{\varkappa} \times\left(t_{c}-t_{\varkappa}\right)\right],\right.
$$

Где $\rho_{ж}, \rho_{c}-$ плотность жидкости вдали от стенки $\left(\mathrm{t}_{ж}\right)$ и при температуре стенки $\left(\mathrm{t}_{\mathrm{c}}\right)$.

Представленные зависимости в дальнейшем были использованы для расчета теплообмена на участках ЛНД системы питания автомобильного дизеля при соответствующих температурах окружающей среды, подкапотного пространства и топлива.

1. Теоретическое определение коэффициента теплопередачи для плоской и цилиндрической стенки

Для практических расчетов установившегося теплового потока при расчетах теплопередачи от одной жидкой (или газовой) среды к другой, отделенной от первой твердой стенкой, использовались классические зависимости, $[3,4]$.

В топливном баке теплообмен между наружной поверхностью топливного бака и окружающим воздухом при движении автомобиля следует рассматривать как вынужденную конвекцию. Теплообмен между внутренней поверхностью топливного бака и топливом можно считать свободной конвекцией.

Из теории теплообмена известно, что при конвективном теплообмене коэффициент теплоотдачи является сложной функцией, зависящей от физико-химических свойств теплоносителей $(\mu, C, \lambda, \rho)$ формы $(\Phi)$ и размеров поверхности теплообмена $(V)$, характера течения $(X)$ и скорости движения среды $(W),[3,4]$ :

$$
\alpha=f(\mu, C, \lambda, \rho, \Phi, X, W),
$$

Для практического изучения влияния различных факторов на коэффициенты теплоотдачи от внешней среды, $\alpha_{1}$ и от внутренней поверхности стенки, $\alpha_{2}$ целесообразно применить теорию подобия и размерный анализ. Конвективный теплообмен характеризуется пятью числами подобия: числом Нуссельта $\mathrm{N}_{\mathrm{u}}$, числом Эйлера $\mathrm{E}_{\mathrm{u}}$, числом Прандтля $\mathrm{P}_{\mathrm{r}}$, числом Грасгофа $\mathrm{G}_{\mathrm{r}}$ и числом Рейнольдса $\mathrm{R}_{\mathrm{e}}$ $[2,3,4]$. 
Поскольку число Нуссельта содержит неизвестный коэффициент теплоотдачи, оно является определяемым критерием. Таким же критерием является число Эйлера, содержащее показатель, характеризующий величину гидравлического сопротивления при движении жидкости. Числа подобия Критерии $\mathrm{P}_{\mathrm{r}}, \mathrm{G}_{\mathrm{r}}$, $\mathrm{R}_{\mathrm{e}}$ являются определяющими критериями. При конвективном теплообмене в случае вынужденного движения жидкости и при развитом турбулентном режиме критериальная зависимость может быть представлены в виде [2,3]:

$$
\mathrm{N}_{\mathrm{u}}=\mathrm{f}\left(\mathrm{R}_{\mathrm{e}}{ }^{*}, \mathrm{P}_{\mathrm{r}}{ }^{\text {* }}, \mathrm{P}_{\mathrm{r}}{ }^{\mathrm{T}}\right) \text {, }
$$

Индексы «ж» и «ст» означают, что соответствующие физические параметры выбраны при средних температурах жидкости и стенки.

Получив зависимости критерия Нуссельта от критериев $\mathrm{R}_{\mathrm{e}}, \mathrm{G}_{\mathrm{r}}, \mathrm{P}_{\mathrm{r}}$ можно определить расчетный коэффициент теплоотдачи от поверхности топливного бака к топливу:

$$
\alpha_{ж} \times \mathrm{N}_{\mathrm{u}} / \mathrm{h},
$$

где $h$ - высота поверхности контакта топлива и стенки бака, м.

Критическими значениями критерия Рейнольдса необходимо считать: $\mathrm{R}_{\text {екр1 }}=2300$ и $\mathrm{R}_{\text {екр} 2}=10000, / 2 /$. Между этими значениями находится переходная область: при малых скоростях поток разделяется на пограничный слой, через который теплообмен осуществляется теплопроводностью, и турбулентное ядро.

При ламинарном движении $\left(\mathrm{R}_{\mathrm{e}}<2300\right)$ наряду с вынужденной конвекцией будет иметь место естественная конвекция, которая возникает вследствие разности температур стенок и топлива и определяющее значение она будет иметь в топливном баке.

1.1 Теплообмен при естественной конвекции на плоской стенке

Расчет средней теплоотдачи вертикальной стенки при свободной конвекции жидкости и газа в сравнительно большом объеме при значениях $\mathrm{P}_{\mathrm{r}}>0,7$ производится по зависимости [5]:

$$
N_{u}=C \times\left(G_{r} \times P_{r}\right)^{n} \times \varepsilon_{t},
$$

Значения коэффициентов «С» и «n» в уравнении (10) для топлива, находящегося в топливном баке следует рассматривать при значении критериев, $[5,6]$ :

$$
10^{3}<\mathrm{G} \times \mathrm{P}=\left(\mathrm{g} \times \beta \times \Delta \mathrm{t} \times \mathrm{h}_{0}{ }^{3} / \mathrm{v}^{2}\right) \times v / \alpha<10^{9}
$$

где $h_{0}$ - высота топлива в баке, м. Тогда $n=0,25, C=0,54$.

Определяющей температурой, по которой выбираются значения физических параметров $\lambda, v, \alpha /, \beta$ теплоносителя, является температура: $t=0,5\left(t_{c т}+t_{ж}\right)$, где $t_{\text {ст }}-$ постоянная или средняя температура стенки; $t_{\text {ж }}$ - температура жидкости вдали от стенки. Температурный напор: $\Delta t=t_{c т}-t_{\text {. }}$. оо отдельным участкам ЛНД

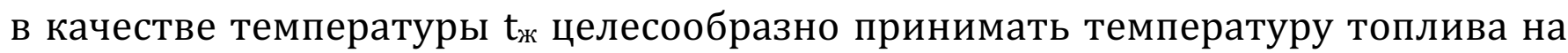
входе в участок (температуру набегающего потока).

При больших температурных напорах, когда в случае капельной жидкости $\left(0,6<\mu_{ж} / \mu_{c}<1,5\right)$, физические параметры в уравнении (10) выбираются при температуре $t_{ж,}$ а найденные значения коэффициента теплоотдачи $\alpha$ умножается на поправочный коэффициент: $\varepsilon_{\mathrm{t}}=\left(\mathrm{P}_{\text {кж}} / \mathrm{P}_{\text {rст }}\right) \times 0,25$. Критерий $\mathrm{P}_{\text {гст }}$ рассчитывается при значении параметров соответствующих температуре стенки; $t_{c т .} \mu_{ж,} \mu_{c}-$ динамическая вязкость жидкости (топлива), соответственно при температуре $t_{ж,}, t_{\text {ст. }}$ 
Коэффициент $\varepsilon_{\mathrm{t}}$ учитывает зависимость вязкости от температуры и влияние направления теплового потока. При нагревании жидкости $\left(\mathrm{t}_{\mathrm{cr}}>\mathrm{t}_{\text {ж}}\right)$ отношение $\mathrm{P}_{\text {кж}} / \mathrm{P}_{\mathrm{rct}}>1$.

Среднюю теплоотдачу при свободной конвекции на горизонтальной стенке при ламинарном режиме можно рассчитать по зависимости [6]:

$$
N_{u}=C \times\left(G_{r} \times P_{r}\right)^{n}, \times\left(G_{r} / P_{r}\right)^{0,25}
$$

где $C=0,5, n=0,25$. При $(G r \times P r)<2 \times 107: n=1 / 3, C=0,135$.

В данной зависимости определяющим линейным размером при расчете критерия $\mathrm{G}_{\mathrm{r}}$, является размер, характеризующий площадь горизонтальной стенки.

В ряде случаев, при физическом моделировании процессов теплообмена при свободной конвекции целесообразно использовать зависимость вида, [6]:

$$
N=\left(G_{r} \times P_{r}\right)^{0.25} \times f\left(P_{r}\right),
$$

где $\mathrm{f}\left(P_{r}\right)=($ от 0,4 до 0,7$)$ при $P_{r}=($ от 0,1 до 100).

Средний коэффициент теплообмена определятся по уравнению:

$$
\left(F_{2} \times \alpha_{2}+F_{8} \times \alpha_{B}\right) / F_{2} \times F_{B}
$$

1.2 Теплообмен при вынужденном движении в трубопроводах

Для оценочных расчетов теплоотдачи при турбулентном режиме целесообразно пользоваться приведенным ниже уравнением М.А. Михеева, которое справедливо в области значений $104<\mathrm{R}_{\mathrm{e}}<2 \times 105$ и $0,7<\mathrm{P}_{\mathrm{r}}<150,[4,7]$ :

$$
N_{u}=C \times R_{e}^{0,8} \times P_{r}^{0,43} \times \varepsilon_{t},
$$

где $C=0,021$ при значении $0,7 \leq P r \leq 1$ и $C=0,023$ при значении $2 \leq P_{r} \leq 150$.

$\varepsilon_{t}-$ поправка на изменение физических свойств жидкости, в зависимости от температуры, смотри уравнение (10).

Аналогичный вид имеет уравнение в преобразованном виде по данным источника [2]:

$$
N_{u}=0,01106 \times R_{e}^{0,75} \times P_{r}^{0,25},
$$

Процесс теплообмена при ламинарном движении жидкости в трубах при оценочных расчетах можно описать критическим уравнением М.А. Михеева [4]:

$$
N_{u}=1,4 \times\left(R_{e v c} \times \frac{d}{l}\right)^{0,4} \times P_{r o c}^{0,33} \times\left(\frac{P_{r o c}}{P_{r c}}\right)^{0,25},
$$

где индексы «ж» и «с» указывают на то, что физические свойства жидкости определяются при средней температуре жидкости и стенки соответственно.

В переходной зоне $\left(2300 \leq \mathrm{R}_{e} \leq 104\right)$ теплоотдачу можно рассчитать по интерполяционному соотношению [6]:

$$
\frac{N_{u}}{N_{u T}}=\gamma+\frac{(1-\gamma) N_{u \tau}}{N_{u T}}
$$

где $N_{u т}$ и $N_{u r}$ определяют по приведенным выше зависимостям для ламинарного и турбулентного режимов;

$\gamma$ - коэффициент, показывающий долю времени, в течение которого наблюдается турбулентный режим; оценивается соотношением [6]. 


\section{Список используемых источников:}

1. Файнлеб Б.Н. Топливная аппаратура автотракторных дизелей. Л.: Машиностроение.1990. 352 c.

2. Кутателадзе С.С. Теплопередача и гидродинамическое сопротивление. М.: Энергоатомиздат, 1990. $367 \mathrm{c.}$

3. Нащекин В.В. Техническая термодинамика и теплопередача. М., 1980. 469 c.

4. Михеев М.А., Михеева И.М. Основы теплопередачи. М.: Энергия, 1977. $344 c$.

5. Тепло- и массообмен. Теплотехнический эксперимент /Е.В.Аметистов, В.А.Григорьев,

Б.Т.Емцов и др.; М.:Энергоиздат,1982. 512 с.

6. Практикум по теплопередаче / А.П.Солодов, Ф.Ф.Цветков, В.В.Елисеев, В.А.Осипова.

М.: Энергоатомиздат, 1986. 296 с.

7. Теплотехнический справочник. М.: Энергия, 1975.

(C) 2017, Жигин В.И.

Теоретические основы оценки теплообмена в линии низкого давления системы питания дизелей (c) 2017, Zhigin V.I.

The theoretical basis for the estimation of heat transfer in low-pressure line of the power supply system of diesel engines 